\title{
Transportation Pods for Transport of COVID - 19 Patients
}

\author{
Sundeep Vijayaraghavan ${ }^{1}$, Nitu Puthenveettil ${ }^{2 *}$ \\ ${ }^{1}$ Professor Department of Plastic Surgery, ${ }^{2}$ Associate Professor, Department of Anaesthesiology and \\ Critical Care, Amrita Vishwa Vidyapeetham, Amrita Institute of Medical Sciences, \\ Kochi, Kerala, India
}

Editor, Corona virus is a highly infectious disease. Human-to-human transmission occurs by droplet, contact, fomites and environmental contamination. ${ }^{1}$ Studies have shown that SARSCoV-2 aerosol distribution might reach up to $4 \mathrm{~m}^{2}$. Patients may require to be transported from operation theatre to ICU and radiology suites. The risk of nosocomial spread of the disease is high during transport of patients. Haphazard transport of infected patients can put health care workers involved at risk of getting infected. Hence it is essential for every hospital to have policies to safely transport patients in transportation pods. But in the current scenario, commercially available transportation pods are difficult to obtain because of the high global demand. Lockdown in most parts of the world and the ongoing travel restrictions have made it more difficult. Hence, we designed "patient transportation pods" in house with the resources available in our institution to minimize and contain risk during transport of infected patients.

Our patient transportation pod has a transparent box at the head end which could be used as an intubation/ extubation box and a transparent polythene sheet attached to it to cover the patient completely. The head piece is made of acrylic, which is cheap, strong and easily available. It has openings with a glove port and cover for the passage of hands during intubation. A similar opening on the right side is used for assistance during airway related procedures and for breathing circuits during transport of patients.

*Correspondence: Nitu Puthenveettil

E mail: nituveesundeep@gmail.com

(iD) https://orcid.org/0000-0003-1303-5619

Received: $22 / 06 / 2020$

Accepted: $28 / 07 / 2020$

DOI: http:/doi.org/10.4038/slja.v29i1.8620

\section{Figure 1}

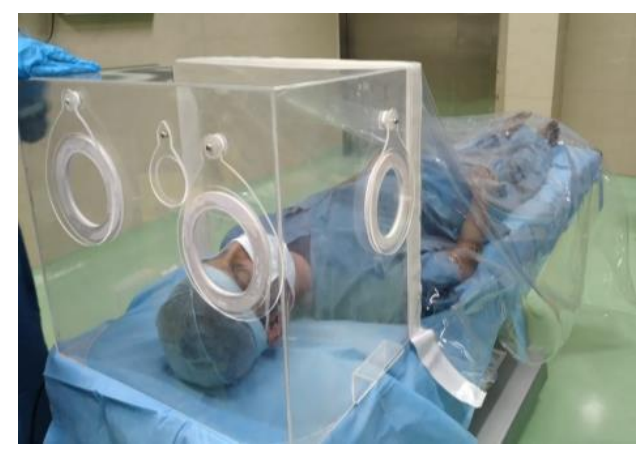

Proper planning is required when intra hospital transportation of a COVID patient is necessary. Security team wearing triple layered mask should lead and ensure clearance of bystanders in the route of transport. Staff responsible for shifting and care of the patient should be in WHO recommended personal protective equipment (PPE) which includes N95 masks, gloves, goggles, head covers, and Hazmat suits. Use of transportation pod provides additional protection. Separate lifts have to be assigned if elevators are required. Utmost care should be taken while donning and doffing to avoid transmission of the disease to the health care worker.

The transport pod could also be used in transporting intubated patients in the ambulance. In an ambulance if there is a door connecting the driver and health compartment, the passage has to be sealed. ${ }^{3}$ The head piece of the pod after use could be decontaminated using $70 \%$ alcohol or $1 \%$ sodium hypochlorite spray. The transparent sheet could be changed after each use.

\section{References}

1. Malhotra N, Joshi M, Datta R, BajwaSJ, Mehdiratta L. Indian society of anaesthesiologists (ISA National) advisory andposition statement regarding COVID-19. Indian J Anaesth 2020; 64: 259-63

https://doi.org/10.4103/ija.ija_288_20 PMID: 32362681

2. Guo Z-D, Wang Z-Y, Zhang S-F, Li X, Li L, Li C, et al. Aerosol and surface distribution of severe 
Puthenveettil et al. Sri Lankan Journal of Anaesthesiology: 29(1): 75-76 (2021)

acute respiratory syndrome coronavirus 2 in hospital wards, Wuhan, China, 2020. Emerg Infect Dis. 2020 Jul.

https://doi.org/10.3201/eid2607.200885

PMID: 32275497

3. Ferioli M, Cistermino C, Leo V, Pisani L, Palange $P$, Nava S. Protecting healthcare workers from SARS-CoV-2 infection: Practical indications. Eur Respir Rev 2020; 29. pii: 200068.

https://doi: 10.1183/16000617.0068-2020

PMID: 32248146 